\title{
Affirmation and Negativity in Spinoza: A Response to Hasana Sharp
}

\author{
Matthias Fritsch
}

In the time allotted to respond to this fascinating book, I will allow myself a few critical questions, coming from outside of Spinoza scholarship. I will assume familiarity with the book. I hope all of my comments, whether of the order of critique or clarification, will be taken as invitations to hear more about this exciting project.

How does the "ethics of similitude" (Sharp 2011, 100, citing A. Matheron) relate to what has been called an "ethics of difference" (whose meaning I leave implied to capture a wider array of concerns)? Ethics here can be taken in at least two different senses: that of normative theory and, more common in continental philosophy, that of a social ontology. In the latter sense, ethics means, roughly, accounting for the way in which beings situate themselves in their place and time, make a home for themselves and for others, critically relating to inherited contexts in doing so. I take it Matheron and Sharp mean the social-ontological sense by the phrase 'ethics of similitude.' Key to the politics of naturalization is the move from a purely normative to an ontological register of doing political theory (10). In contemporary environmental ethics, for example, relations with the natural environment, or nonhuman entities therein, are considered merely under the aspect of whether normative terms developed within and for human moral and 
political contexts can be "extended" to them. By contrast to the infelicitous confusions resulting from e.g. Rawls's "problems of extension” (Rawls 1996, 20-21) -as if a concept of justice developed for the contemporary domestic realm could simply be extended to nondomestic and intergenerational others, to the disabled and to animals - Sharp convincingly argues that we first need a different political ontology, one that takes our constitutive relations with 'nature' seriously. And that means rethinking nature in general.

Taken in this sense, what drives Spinozistic ethics is conatus, the drive to persevere by joyfully joining one's forces with others. I wonder whether similitude does justice to the force of difference and of a negativity whose conception need not be Hegelian through and through. In seeking to capture why and how Hegel and Spinoza offer alternatives to liberal political theoryand Sharp may seem to imply that they are the only ones to do so (118)—Sharp rejects, with good reason, the wide-spread "binarism of affirmation and negation" as too Hegelian (120). Instead, she wishes to replace emphasis on this opposition, common to theorists from Hegel himself to Deleuze, with their respective "models of relationality" and their conceptions of desire, with Hegel stressing representation and recognition among humans and Spinoza composition among human and nonhuman forces (121). As desire is understood primarily as an affirmation of one's relationally constituted self, however, the issue of affirmation and negation resurfaces even there where the attempt to rethink the opposition between the human and the natural moves into the foreground.

On Sharp's reading of Spinoza, conatus names an affirmation of oneself as singular existence, a striving to persevere in one's unique non-generic being, a "desire for life" (133). Given the relational ontology meant by "infinite nature," conatus is of course not the sole cause of self-preservation. In affirming my own "self-maintenance" and unique "distinctness," I must 
at the same time affirm my dependence on others. Before referring us back to her rich discussion of transindividuality in Chapter One, Sharp rightly states, "Our most fundamental power to be cannot ultimately be separated from the concurrent forces of other beings," (133). It is this duplicity of the conatus-affirming distinctness yet relationality, independence and yet dependence, and so on - that installs in the conatus, it seems to me, a fundamental negativity, the impossibility of ever resting content, of being joyfully one with oneself.

It appears, however, that it is this conflict within the conatus as "self-affirmation" that Sharp's Spinoza does not allow when he contrasts conatus with death on the basis of an insideoutside distinction. Sharp writes, “...conatus implies that a thing cannot be self-opposed in essence," (134) before citing the Ethics: "No thing can be destroyed except through an external cause" (E IIIp4). She continues, "Pace Hegel and Freud, negation is [now citing Macherey] 'fundamentally extrinsic to the nature of things"” (134). We note that here, the opposition between Hegelian negation and Spinozist affirmation re-emerges as crucial. By contrast, one need not subscribe to Hegelian dialectics-in particular not to its emphasis on Geist, on recognition for one's status as a human person above nature, and on teleological development in a life-and-death struggle - to make the point that affirmation and negation need to be seen as conflictually co-implicated in a way that need not rule out some priority to affirmation, but that is not captured on the model of inside and outside. For this pair of terms should be viewed by relational ontologists with the same suspicion as the pairs part-whole and individual-aggregate, terms Sharp advisedly sets aside when reading Spinoza's relationality through the work of Gilbert Simondon in Chapter One (35). 
Let me elaborate why self-affirmation— perhaps similar to Butler's reading ${ }^{1}$ — cannot just affirm life without also affirming death, thus that which Sharp claims is outside, the "external" causes of death. The elaboration comes in three steps.

(a) First, if conatus affirms the life of the self, but "cannot ultimately be separated from the concurrent force of other beings" (133), then conatus affirms the (life of) these other beings at the same time and, in the end, in indistinguishable ways. Given the many other beings and things on which I depend, it seems I cannot even limit the affirmation of others to those similar to me, even if it appears at first 'natural' and advisable to love those who love me, and to love what they love, hate what hinders their power and makes them sad, etc. (139-40). So in affirming the other, do I not affirm much more than just the way in which the other can enhance my conatus through her similarity to me?

(b) The second step would then lie in the recognition that an affirmation of "the concurrent force of other beings" and external causes is also an affirmation of what Spinoza calls infinite substance, God, or nature, that is, the "infinity" of inexhaustible differentiation and recomposition that sustains the self (36, cf. 133, and all of Chapter One on Simondon and 'transindividuality'.) This helps make sense of the stress that is placed by Spinoza on "love of nature" (99), a love we will wonder about below. To affirm the self is to affirm the other, and to affirm other beings is to affirm all the other others (an 'all' to be problematized). Other beings, however, are altered by their constitutive relations, just like me, and so engaged in similar processes of seeking self-affirmation.

This is not a temporal progression that starts with a given self, but rather one that continually (and discontinuously, as the next point has it) re-emerges intermittently, as it were, on this tour that is more than a circular detour. I am never what I am, as Sharp says: "one must 
perpetually mutate in order to remain what one is" (133). As she puts it in discussing Simondon: "The transindividual is a paradoxical concept that defers perpetually the affirmation of individual reality per se" (36). Affirming infinite nature, then, highlights that there is no return to a preexisting self. What is here called nature, the infinity of relations and recompositions with other beings engaged in similar processes of relating, both sustains and, in the same gesture, reabsorbs the self, as something larger beyond it.

One may speculate that this is also the reason why illusions of freedom, of independence and of distinctness, prove difficult, perhaps impossible, to uproot (67). Affirmation aims at a self that, however, does not pre-exist this affirmation. It is led on a tour that never comes back to the same self. And so the self must think of itself as affirmable, isolatable, or separate in order to first of all affirm itself, even if that is, theoretically, recognized as strictly speaking impossible.

(c) Third, if self-affirmation seeks to aim at itself but must accept a kind of detour through and with others, a detour that cannot come back to the "same" self as this self is only in the process of becoming and mutation on this tour, then affirmation of life is also an affirmation of death. For to affirm myself I must affirm the other, thus infinity, thus that which also entails my mutation, and so my death. To affirm myself is to affirm that from which I live, but also that which is already in the process of re-absorbing me. To affirm the other is thus not just a question of affirming myself; in it, I also affirm my mutation, whose mineness is indeed not easy to account for without an underlying subiectum. If, once more, "one must perpetually mutate in order to remain what one is" (133), then perpetual mutation is what "I" seek to preserve, and that is not just my life but my death. Hence, conatus is also a drive to overcome one's present self, to let it die so that another may be born. Conatus should not be opposed to death, as if death only ever came from the outside (134). 
This point is importantly not identical to Hegel's critique of Spinozistic desire, as Sharp traces it. To acknowledge the negativity in self-affirmation and in the desire to live is not necessarily to ascribe to desire the telos of further development, a development that Hegel argued calls for the confrontation with another self-consciousness in a life-and-death struggle for recognition that is then said to be unique to human beings. The negativity I just sketched is not limited to human beings, nor need it aim at recognition (despite the intense instability in which it constitutes any 'self') or be limited to recognition from another self-consciousness. Desire need not be re-inscribed in a humanist politics of recognition which aims at being recognized for being a human person defined by its non-natural status. Here it seems to me that Sharp's contrast between recognition and conatus, between life and death, between eros and thanatos, may be too strong.

It is precisely constitutive relationality, then, that reveals the nonbinary co-implication of affirmation and negativity. Two further points are connected to this co-implication of life and death. The first (point 2) concerns the way in which Sharp's attempt to cast negation on the outside of affirmation is linked, in the discussion of Spinoza vs. Hegel, to the contrast between relations with nonhuman nature and relations with humans. This happens in part by way of a double entendre in the word 'nature'. The second corollary (point 3) concerns the role of 'love of God' in the politics of naturalization.

\section{II}

Lucidly, Sharp recognizes a number of shortcomings in the "binarism of affirmation and negation" (120), and she finds much of value in Hegel in the course of offering illuminating comparisons of Hegel and Spinoza in great detail beyond binary oppositions. And yet, toward the 
end of Chapter Four Sharp contrasts once more the Hegelian project of "socializing" desire with the Spinozistic attempt at "naturalizing" it (138). Hegel's politics of recognition is humanist to the extent that it depends on elevating humans out of nature. By contrast, the politics of renaturalization understands that we live "in an epoch where the risk of too much man is arguably greater than the risk of too much nature" (139). Hence, Sharp recommends that "we first transform our relationship not to human others but to God or nature itself' (138, my emphases). The nature in question here is opposed to human sociality: "air, sound, and water quality, the organization of space, and the character of relations with nonhuman animals" are mentioned as forces of the nonhuman world on which "our life-worlds" also depend (153).

But if for Sharp and Spinoza 'nature' is the term for the infinite de- and re-compositions in which beings come to be and pass away, then the distinction between, on the one hand, a politics in which we seek different relations with humans, and, on the other, a politics in which we first transform our relation to God or nature (in the direction of 'love', I take it—see point 3), seems difficult, if not impossible, to make. I wonder whether there is here a tendency on the part of Sharp to slide from a commonsensical to a Spinozistic meaning of nature. The first meaning of 'nature' intends the nonhuman world (as in the passages just cited), the second, Spinozistic meaning refers to the relations between beings in an unsurpassable 'whole,' including humans and nonhumans. This second meaning of nature does not very well permit the opposition between first fixing our intersubjective relations or first getting our relation to nature right. Already to relate to myself is to relate to many human and nonhuman others in relation to which I struggle to remain myself. Given the utter neediness with which humans are born of this nature, with ongoing needs for both material things and for love and acceptance, humans depend on other humans above all (even if Spinoza would not be surprised to learn of humans raised by 
wolves, as Sharp writes). There is thus nothing surprising in Spinoza's claim that "man is most useful to man," and one may in fact see this claim as following - due to our biological and psychological make-up — from the fact that we are inextricable parts of nature.

It is one thing to say that interhuman relations, to the extent we can separate them from relations to nonhumans, should not be construed as primarily oriented toward a life-and-death struggle aiming at being recognized as free persons elevated out of nature. It is quite another to conclude from this anti-Hegelian point that we should first understand ourselves as parts of a nature that does not include humans. It seems the correct conclusion from the anti-Hegelian point, to the extent we go along with it, would be that we should seek to acknowledge the way in which both we and our human others are part of 'nature' in the infinite sense in which Spinoza speaks of it as a substance prior to the division between the human and nonhuman world. The "vulnerability to death" whose use by Hobbes, Hegel and Butler to "inflate the power of the social to the detriment of natural determination" (Sharp 121) Sharp criticizes may then first of all be seen as precisely the most natural determination. Death here stands in for that which the self cannot master, but to which it must be exposed, in general rather than in a struggle for recognition, in order to become itself.

\section{III}

This nature - a nature whose infinite de- and re-compositions imply that no one of its elements ever coincides with itself, so that each human is vulnerable to a death threatened by Hobbes' weakest upon the strongest (Hobbes, Leviathan, chapter XIII) as well as by Val Plumwood's crocodile (Plumwood 2008) — seems hard to love in toto, let alone able to unite a political community in such love. This takes us to the politics of renaturalization. Here Sharp 
envisions a political project in which humans experiment with variable and expanding forms of human association "to discover new joys and passions" (105). One may here worry that the tendency to stress affirmation over negation leads to stressing composition over decomposition, joy over rejection, love over hate, and friendship over enmity. This worry would find its most political expression in the vision of a love of nature understood as a whole to which corresponds a "total human community" (105) whose unifying "highest good" is expressly "nonrivalrous" (99).

Before I express these worries any further, I want to note that here too, Sharp's account, as far as I can see, pulls in different directions. It stresses the co-implication of affirmation and negation, of unification and differentiation beyond holism, in several places. For instance, in the first chapter Sharp turns to Simondon's relational ontology in order to account for individuation in Spinoza. In this context, she writes: "There simply are no atoms... But neither are there wholes... Being is a system of relations that is excessive, always incomplete and uncompleted, and perpetually differentiating" (36). Applying this insight to Spinoza, she writes that "his image of nature as a 'whole' or 'totality' is thus perplexing" (37-8).

However, if this perplexing wholeness is ontologically impossible and returns in the troublesome idea of a nonrival good (99) that politics recommends we collectively pursue as our "universal common good" (104), would it not be better to go all the way in reading Spinoza with Simondon? Can nature, this system of differentiation that disallows my coincidence with myself, and that "does not always provide" (137), simply be loved without also being deplored? Would we not have to account for material scarcity, the inevitably ensuing competition for scarce goods, to have a clearer account of the origin of the blindness of desire and insatiable greed (E I app., 
cited 137), rather than join in Spinoza's "lament about the irreducibility of passions and our tendency toward enmity" (104)?

\section{Notes}

${ }^{1}$ A careful reading of Butler's article on Spinoza's conatus (Butler 2006), and Sharp's response to it (Sharp 2007), as referenced briefly toward the end of chapter four (150), might shed further light on the issues discussed here.

\section{Works Cited}

Butler, Judith. "The Desire to Live: Spinoza's Ethics under Pressure" in: Politics and the Passions, 1500-1850, ed. V. Kahn, N. Saccaman, and D. Coli. Princeton: Princeton University Press, 2006.

Plumwood, Val. "Tasteless: Towards a Food-based Approach to Death." Environmental Values 17 (2008): 323-330.

Sharp, Hasana. "Melancholy, Anxious, and Ek-static Selves: Feminism between Eros and Thanatos" Symposium: Canadian Journal of Continental Philosophy 11, no. 2 (2007): 313-31.

2011.

. Spinoza and the Politics of Renaturalization. Chicago: University of Chicago Press, 